\title{
Assessment of Moisture Performance of National Building Code Canada Compliant Wall Assemblies under Climate Change
}

\author{
Max Junginger ${ }^{1}$, Maurice Defo ${ }^{2}$, Travis Moore ${ }^{3}$, Michael A. Lacasse ${ }^{4}$ and \\ Vanderley M. John ${ }^{5}$ \\ ${ }^{1}$ Polytechnic School, University of São Paulo, São Paulo, SP, Brazil. Maxjgg@gmail.com \\ ${ }^{2}$ Construction Research Centre, NRCC, Ottawa, ON, Canada, Maurice.Defo@nrc-cnrc.gc.ca \\ ${ }^{3}$ Construction Research Centre, NRCC, Ottawa, ON, Canada, Travis.Moore@nrc-cnrc.gc.ca \\ ${ }^{4}$ Construction Research Centre, NRCC, Ottawa, ON, Canada, Michael.Lacasse@nrc-cnrc.gc.ca \\ ${ }^{5}$ Polytechnic School, University of São Paulo, São Paulo, SP, Brazil, Vanderley.John@lme.pcc.usp.br
}

\begin{abstract}
Due to climate change, higher temperatures and rainfalls are expected to happen in some areas of Canada, which might increase the climate loads on buildings and lead to premature degradation of moisture-sensitive materials in wall assemblies. To investigate potential durability issues in three cities across Canada (Ottawa, Vancouver and Calgary), code-compliant wood-frame walls with two types of claddings, stucco and brick, were simulated using Delphin 5.9. Two different climate data sets, historical and future when a global warming of $3.5^{\circ} \mathrm{C}$ is expected to be reached were used. The hygrothermal performance in terms of mold growth risk was analysed with respect to cladding types, considering air leakage. All the three cities are similarly warmer in the future. However, wind-driven rain (WDR) is higher in Vancouver than in Ottawa and Calgary. With brick cladding the relative humidity is kept below the threshold for mould development only in Ottawa and Calgary. With stucco in future, while Ottawa shows greater mould indices than historical, Calgary shows opposite behavior. The results suggest that the risk of mould growth due to air leakage may decrease in the future.
\end{abstract}

Keywords: Code Compliant Walls, Moisture Performance, Climate Resilience, Air Leakage, Stucco Wall, Brick Cavity Wall.

\section{Introduction}

Climate change has received increasing attention globally due to many possible consequences, including building long-term performance issues from temperature increases and more severe and frequent rainfall events. The Intergovernmental Panel on Climate Change (IPCC, 2014) has indicated that climate changes has resulted from anthropogenic action and, whereas temperature changes arising from human influence is indeed a global concern, it is known that in Canada annual average temperatures will rise about twice the global average.

It is also expected that weather extremes will intensify in the future from a warming climate and, even though rainfall events might decrease in some areas, these are likely to increase for over most of Canada (Bush and Lemmen, 2019). In some regions, increases in precipitation as high as $40 \%$ are expected and this will have significant effects on buildings: water infiltration, related mostly to wind-driven rain, will increase accordingly and might pose a higher risk to the premature degradation of moisture-sensitive materials in wall assemblies (Lacasse, Defo, et al., 2018).

To address these issues of moisture accumulation in wall assemblies due to condensation or 
water ingress, the National Building Code (NRC, 2015) set prescriptive requirements for all the walls separating conditioned from unconditioned spaces. These include: i) minimum thermal insulation according to the climate zone; ii) an air barrier system with an air leakage rate not greater than $0.1 \mathrm{~L} /\left(\mathrm{s} . \mathrm{m}^{2}\right)$ at $75 \mathrm{~Pa}$; iii) a vapor barrier with permeance not greater than $60 \mathrm{ng} /\left(\mathrm{Pa} . \mathrm{s.m}^{2}\right)$; and iv) position of low permeance material in the wall. As well, in case where an exterior insulation is added, NBC might also require a minimum ratio between outboard and inboard thermal resistance (NRC, 2015, p. B-9.159). All these technical requirements are intended to minimize the chance of moisture accumulation in wall assemblies, which can lead to deterioration of wood and wood-based building products.

Although the requirements were set based on historical climate loads, item 5.1.4.2 of NBC says that "... assemblies exposed to the exterior shall be resistant to any mechanism of deterioration that may reasonably be expected". As such, the impacts of climate change on moisture performance of code-compliant walls need to be assessed.

The primary objective of this study is to evaluate the moisture performance of code-compliant wall assemblies in both historical and future climate. The approach followed is the one provided in the "Guideline for the Design for Durability of the Building Envelope" (Lacasse et al., 2018).

\section{Methods}

The methodology for the assessment of moisture performance of code-compliant wall assemblies as described in this paper follows the approach given in the "Guideline for the Design for
Durability of the Building Envelope" (Lacasse, Ge, et at., 2018). This approach essentially uses
hygrothermal modelling as means to assess the response of wall components to climate loads
acting on the exterior and envirommental conditions on the interior of the assembly; so, the
moisture performance of the wall can be determined on the basis of the risk of mould growth
or wood decay in wodd based components.

The simulation tool is first described and, thereafter, details in respect to input data for sim-

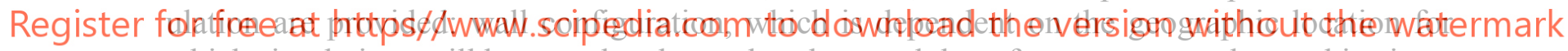
which simulations will be completed; weather data, and the reference years to be used in simulations; boundary conditions, in which boundary parameters are defined; air leakage; and material properties.

\subsection{Geographic Location}

Three cities were selected across Canada: Calgary (AB), Ottawa (ON) and Vancouver (BC), with low, medium and high moisture indices respectively. The main characteristics of the cities are shown in Table 1.

Table 1. Geographic location and climate details about the cities.

\begin{tabular}{c|c|c|c|c|c|c|c}
\hline $\begin{array}{c}\text { City } \\
\text { (Province) }\end{array}$ & $\begin{array}{c}\text { Latitude } \\
\mathbf{(}^{\mathbf{}}\end{array}$ & $\begin{array}{c}\text { Longitude } \\
\mathbf{(}^{\mathbf{o}}\end{array}$ & HDD & Zone & $\begin{array}{c}\mathbf{R S I}_{\mathbf{m i n}} \\
\left(\mathbf{W} / \mathbf{m}^{\mathbf{2}} \mathbf{K}\right)\end{array}$ & MI & $\begin{array}{c}\text { Annual rain } \\
(\mathbf{m m})\end{array}$ \\
\hline Ottawa (ON) & 45.25 & -75.42 & 4440 & 6 & 2.97 & 0.84 & 750 \\
\hline Vancouver (BC) & 49.28 & -123.12 & 3100 & 4 & 2.78 & 1.93 & 1850 \\
\hline Calgary (AB) & 51.05 & -114.07 & 5000 & $7 \mathrm{~A}$ & 2.97 & 0.37 & 325 \\
\hline HDD - heating degree days below $18^{\circ} \mathrm{C}$ \\
RSI - Effective thermal resistance \\
\hline
\end{tabular}




\subsection{Simulation Tool}

A state-of-the-art hygrothermal modelling software, Delphin 5.9, was used to undertake the hygrothermal simulations. The solver parameters were adjusted to $0.01 \mathrm{~s}$ initial time step, $60 \mathrm{~s}$ maximum time step, $10^{-6}$ relative tolerance and $10^{-7}$ moisture mass balance.

\subsection{Wall Configuration}

A wood frame wall of a 3.5-storey (10-m high) residential building located in suburban areas was considered. For each city, two cladding types were simulated: brick and stucco. Figure 1 shows the composition of the brick wall.

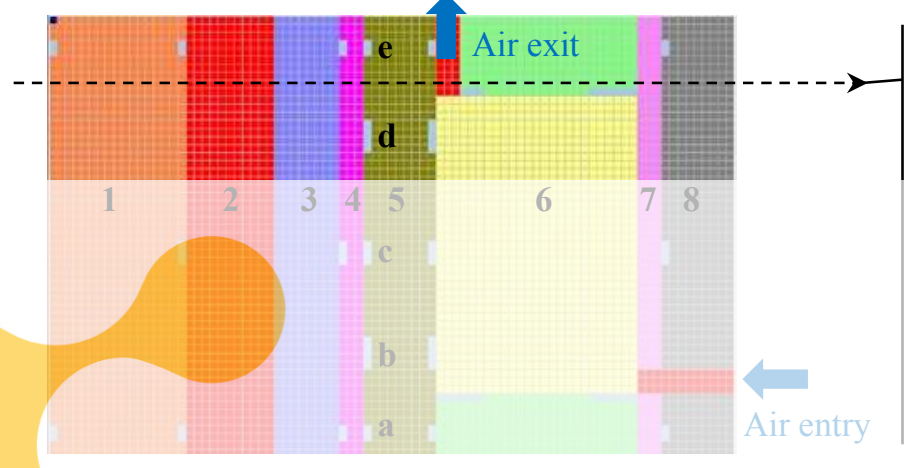

1. Brick

2. Air layer

3. External insulation

4. Sheathing membrane: $30^{\prime}$ paper

5. OSB (11.1 mm)

6. Stud with low density glass fiber

insulation $(140 \mathrm{~mm})$

7. Polyethylene $(6 \mathrm{mil}=0.15 \mathrm{~mm})$

8. Gypsum board (12.7 mm)

Figure 1. Layers of the brick wall and the locations for reading Relative Humidity and Temperature.

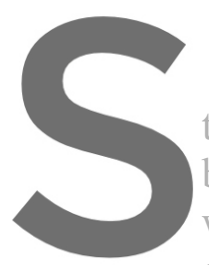

From the sheathing membrane to the interior side of the w
the layers are the same for all walls. The beight of the wall was

of the walls, complete details for each city are given in Table 2.
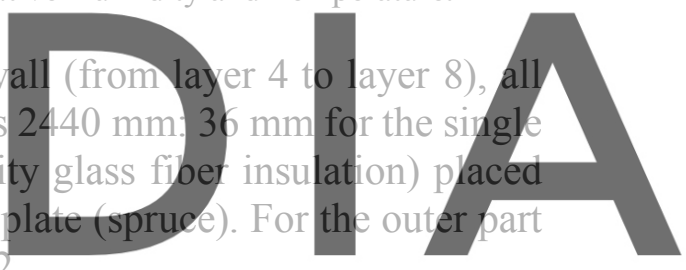

Register for free at https//www.scipedia.@®m. todowat@ad the version without the watermark

\begin{tabular}{|c|c|c|c|c|c|c|}
\hline \multirow{2}{*}{ City } & \multicolumn{2}{|c|}{ Cladding } & \multirow{2}{*}{$\begin{array}{c}\text { Drainage } \\
\text { cavity (mm) }\end{array}$} & \multirow{2}{*}{$\begin{array}{l}\text { External } \\
\text { insulation }\end{array}$} & \multirow{2}{*}{$\begin{array}{l}\text { Air change } \\
(/ \mathbf{h})\end{array}$} & \multirow{2}{*}{$\begin{array}{c}\text { Air } \\
\text { leakage }\end{array}$} \\
\hline & Type & Thick (mm) & & & & \\
\hline Ottawa & Brick; Stucco & $90 ; 19$ & 25; None & EPS $(6.5 ; 12.7 \mathrm{~mm})$ & $10 ;$ None & ith \\
\hline Vancouver & Brick; Stucco & $90 ; 19$ & $25 ; 10$ & None; None & $10 ; 10$ & \\
\hline Calgary & Brick; Stucco & $90 ; 19$ & 25 ; None & $\operatorname{EPS}(6.5 ; 12.7 \mathrm{~mm})$ & 10; None & \\
\hline
\end{tabular}

In Calgary and Ottawa it was necessary to incorporate an external insulation to reach the minimum energy requirement $\left(\mathrm{RSI} \geq 2.97 \mathrm{~W} / \mathrm{m}^{2} \mathrm{~K}\right)$ whereas in the warmer climate of Vancouver $\left(\mathrm{RSI} \geq 2.78 \mathrm{~W} / \mathrm{m}^{2} \mathrm{~K}\right)$ the stud cavity insulation alone was enough.

\subsection{Weather Data}

Two sets of climate data were used: historical and future (when a global warming of $3.5^{\circ} \mathrm{C}$ is expected to be reached). Both sets were prepared according to Gaur et al. (2019) and encompass a 31-year time period, from 1986 to 2016 and from 2062 to 2092. From each set, the median and the wettest years were selected based on the moisture index (Cornick et al., 2003) and were used as moisture reference years for simulations. Those years and the wall orientation with the 
highest wind-driven rain load are summarized in Table 3. In all cases there is an increase in the temperature in the future; RH levels vary quite the same way in Calgary and Vancouver, but are higher in the future climate for Ottawa.

Table 3. Moisture reference years and wall orientation for each city.

\begin{tabular}{|c|c|c|c|c|c|c|c|c|}
\hline \multirow{2}{*}{ City } & \multicolumn{3}{|c|}{ H - Historical data (year) } & \multirow{2}{*}{$\begin{array}{c}\text { Wall orien- } \\
\text { tation }\left({ }^{\circ}\right)\end{array}$} & \multicolumn{3}{|c|}{ F - Future data (year) } & \multirow{2}{*}{$\begin{array}{c}\text { Wall orien- } \\
\text { tation }\left({ }^{\circ}\right)\end{array}$} \\
\hline & Period & Median & Wet & & Period & Median & Wet & \\
\hline Ottawa & \multirow{3}{*}{$\begin{array}{c}1986 \\
\text { to } \\
2016\end{array}$} & 1989 & 1991 & 180 & \multirow{3}{*}{$\begin{array}{c}2062 \\
\text { to } \\
2092\end{array}$} & 2074 & 2070 & 180 \\
\hline Vancouver & & 1988 & 1994 & 145 & & 2091 & 2066 & 180 \\
\hline Calgary & & 2015 & 2016 & 292 & & 2069 & 2063 & 315 \\
\hline
\end{tabular}

\subsection{Boundary conditions}

\subsubsection{Air Leakage}

All the walls were simulated with and without air leakage and the exfiltration path (Figure 1) is one of the worst cases in terms of moisture accumulation suggested by Ojanen and Kumaran (1992; 1996). This path is also the same as the one used by Saber (2014). An air leakage rate of $0.1 \mathrm{~L} /\left(\mathrm{s} \cdot \mathrm{m}^{2}\right)$ at $75 \mathrm{~Pa}$ was tested, which is the maximum rate prescribed by the NBC (NRC, 2015, p. B-5.27) when the indoor relative humidity ranges between 27 and 55\%. An equivalent air leakage area was computed assuming a discharge coefficient of 0.6 and air density of $1.2 \mathrm{~kg} / \mathrm{m}^{3}$. For a $2.4 \mathrm{~m}$ high wall, the area of the orifice is around $35 \mathrm{~mm}^{2}$ at $75 \mathrm{~Pa}$, but since the real pressure differende to $26 \mathrm{~mm}^{2}$ (ASHRAE, combination of wind ancin respectively (Figure a circular shape and its
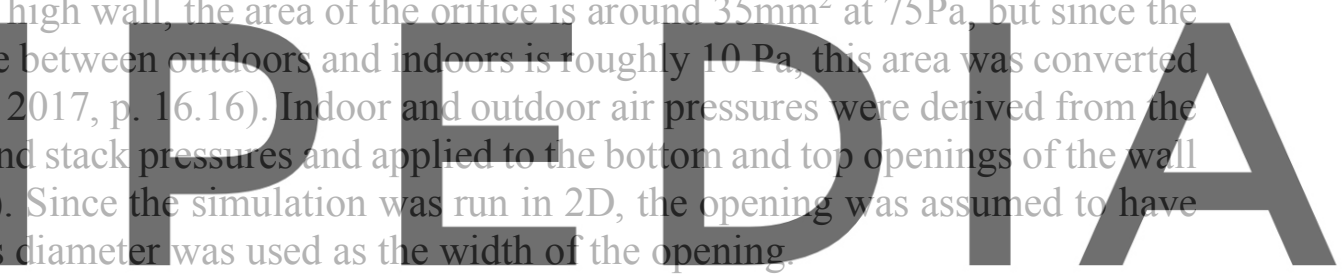

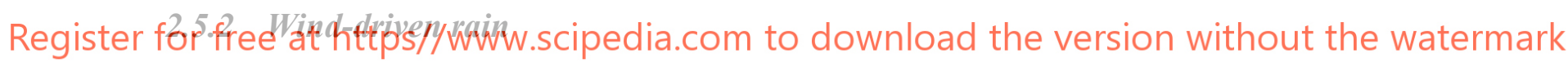
Wind-driven rain (WDR), used as an imposed moisture flux on the exterior surface of the wall, was calculated according to ASHRAE 160 (ASHRAE, 2016, p. 6,7), assuming a 3.5 storey building (10-m high) located in a suburban area. The exposure (FE) and deposition (FD) factors were set to 1.0 and 0.5 respectively. Figure 2 shows the accumulated wind-driven rain for all cities, historical and future.

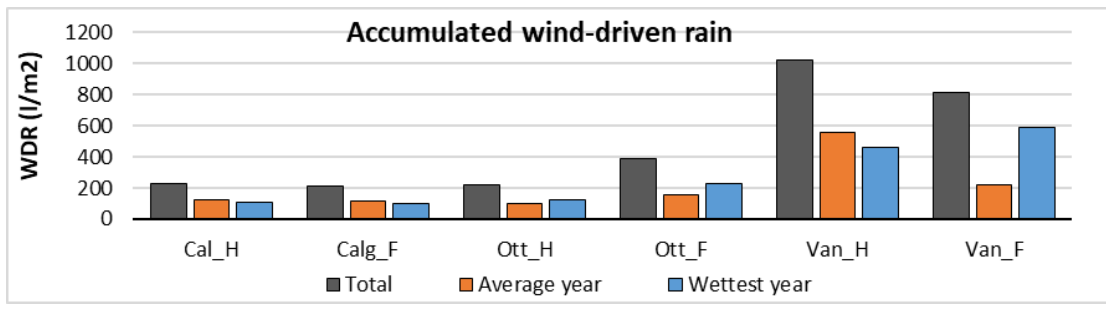

Figure 2. Accumulated wind-driven rain (ASHRAE) for all cities, historical and future.

Calgary has quite the same amount of rain in both scenarios for the two years together; Ottawa shows an increase in the rain in the future for both average and wettest years; Vancouver is less rainy in the future, but there is an important difference between the two years: in the 
future, the average year is about $65 \%$ dryer and the wettest year is about $30 \%$ rainier.

\subsubsection{Other parameters and conditions}

Initial conditions for all layers were set to $21^{\circ} \mathrm{C}$ and $50 \%$, respectively for temperature (T) and relative humidity $(\mathrm{RH})$.

Indoor conditions were calculated using the ASHRAE method, heating only (ASHRAE, 2016, p. 4), which means $\mathrm{T} \geq 21.1^{\circ} \mathrm{C}$ (no upper limit) and $40 \% \leq \mathrm{RH} \leq 70 \%$.

Other coefficients were adopted as follows: outdoor heat transfer coefficient: $4+4 \mathrm{v} \mathrm{W} / \mathrm{m}^{2} \mathrm{~K}$ ( $\mathrm{v}$ is wind speed) (ISO, 2017); indoor heat transfer coefficient: $8 \mathrm{~W} / \mathrm{m}^{2} \mathrm{~K}$; outdoor vapor transfer coefficient: $2.44 * 10^{-8}+2.44 * 10^{-8} \mathrm{v} \mathrm{s} / \mathrm{m}$; indoor vapor transfer coefficient: $1.52 * 10^{-8} \mathrm{~s} / \mathrm{m}$; ground shortwave reflection $=0.1$; shortwave surface absorption $=0.6$; ground longwave emission coefficient $=0.9$; surface longwave emission coefficient $=0.9$.

For wall assemblies having a drainage cavity, the air change per hour $(\mathrm{ACH})$ was set to 10 .

\subsection{Discretization of the Walls}

Preliminary tests simulations with different number of elements were undertaken to select the optimal scheme in terms of accuracy and simulation time. The final mesh used in this paper was composed of 3465 elements for stucco and 4345 for brick.

\subsection{Material Properties}
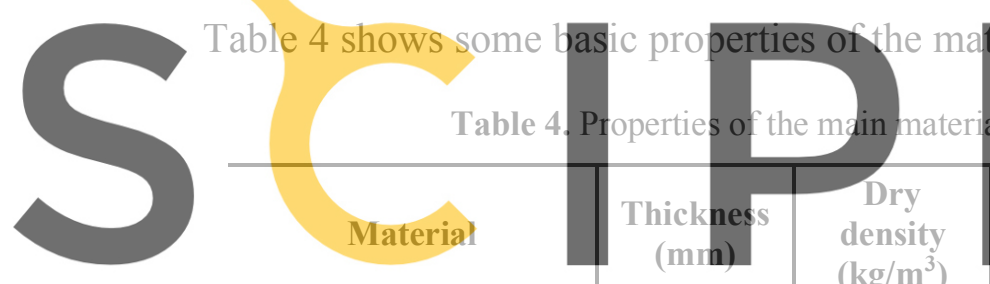

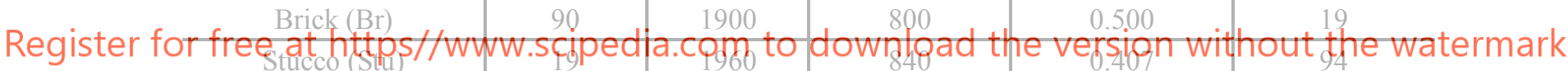
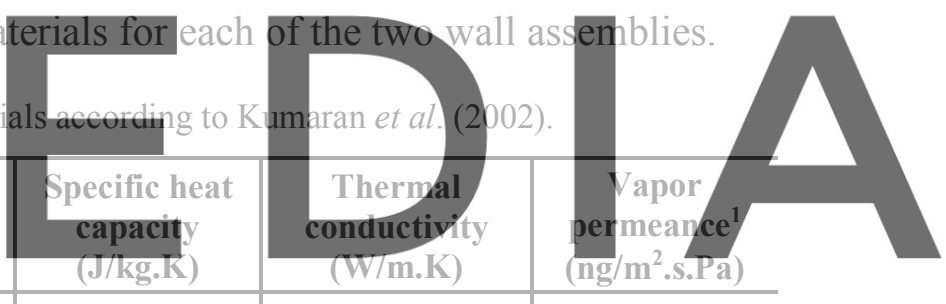

\begin{tabular}{|c|c|c|c|c|c|}
\hline OSB & 11 & 600 & 1880 & 0.094 & 101 \\
\hline Glass fiber batt & 140 & 11.5 & 840 & 0.043 & 990 \\
\hline Vapor barrier $^{2}$ & 0.15 & 1256 & 840 & 0.159 & 60 \\
\hline Sheathing membrane ${ }^{3}$ & 0.22 & 909 & 1256 & 0.159 & 907 \\
\hline 1. Values at $50 \% \mathrm{RH}$ & \multicolumn{3}{|c|}{ 2. $0.15 \mathrm{~mm}$ polyethylene } & \multicolumn{2}{|c|}{ 3. 30' asphalt impregnated paper } \\
\hline
\end{tabular}

\subsection{Performance Assessment}

The performance assessment focused on the mould index calculated according to the VTT model described in Ojanen et al. (2010). It is known that mould growth is a highly complex mechanism which is mostly influenced by relative humidity, temperature, material susceptibility, surface quality (Vereecken and Roels, 2012). Different models use different parameters, and not necessarily the same way and, then, distinct outcomes are expected; a deeper discussion about this is out of the scope of this paper and can be found elsewhere, as in Sedlbauer (2001), Vereecken et al. (2011), Viitanen et al. (2015), Gradeci et al. (2017). In this study, the VTT model was adopted because it is recognized by ASHRAE 160 (ASHRAE, 2016, p. 7).

The index was calculated for many different locations of OSB, bottom plate and top plate, 
assuming a sensitive class for both material and surface, and 0.1 as decline factor (there is no suggestion in ASHRAE for OSB and then 0.1 was adopted as a conservative value). The highlighted squares in Figure 1 show all the locations in the assembly where values of RH and T were acquired. However, the focus of this paper is in the worst position, identified with the letter "c" in Figure 1 (exterior layer of OSB at mid-height); RH and T values used to compute mould index were acquired on a portion with the dimensions of $0.5 \mathrm{~mm} \times 500 \mathrm{~mm}$.

\section{Results and Discussion}

Figure 3 shows the mould index profiles for stucco and brick claddings. Solid lines represent situations with no air leakage and dashed lines with air leakage.

Brick cladding in Vancouver (Figure 3a) develops mould, while in Ottawa and Calgary there is no mould growth. This may be explained by the higher amount of WDR in Vancouver compared to Ottawa and Calgary (Figure 2). In Vancouver, mould index profile is consistently greater for historical than future. In fact, the first year (average year) in the future has a lower amount of WDR, which may explain the fact that there is no mould growth, while the second year has more WDR in future than in historical.

In the case of stucco, mould index profiles were quite similar in Vancouver for both climate scenarios (Figure 3b), which is different to the observations for brick. This may be explained by the fact that stucco cladding has higher liquid diffusivity, smaller thickness, and a drainage cavity of only $10 \mathrm{~mm}$. As such, the liquid water reaches the drainage cavity quickly and maintains high RH levels. mould indices. Ottaw cal. This may be explai torical climate, howeve gary (Figure 3d) shows Figure 3, the WDR in Cal gary is quite similar for-
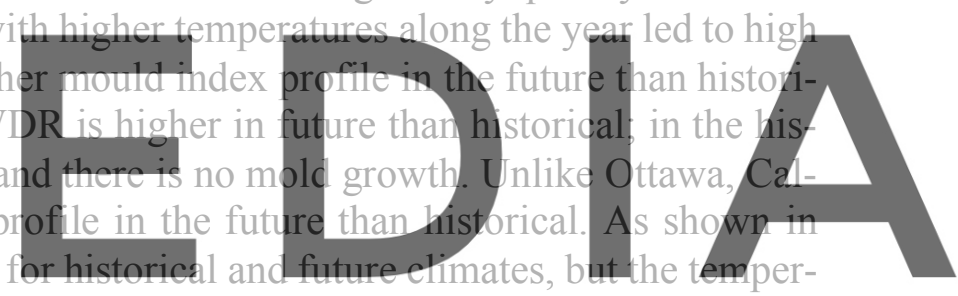

ature is higher and therefore might have increased the drying potential of the whole assembly,

Register forfeesingththtpsy///windicscipedia.com to download the version without the watermark
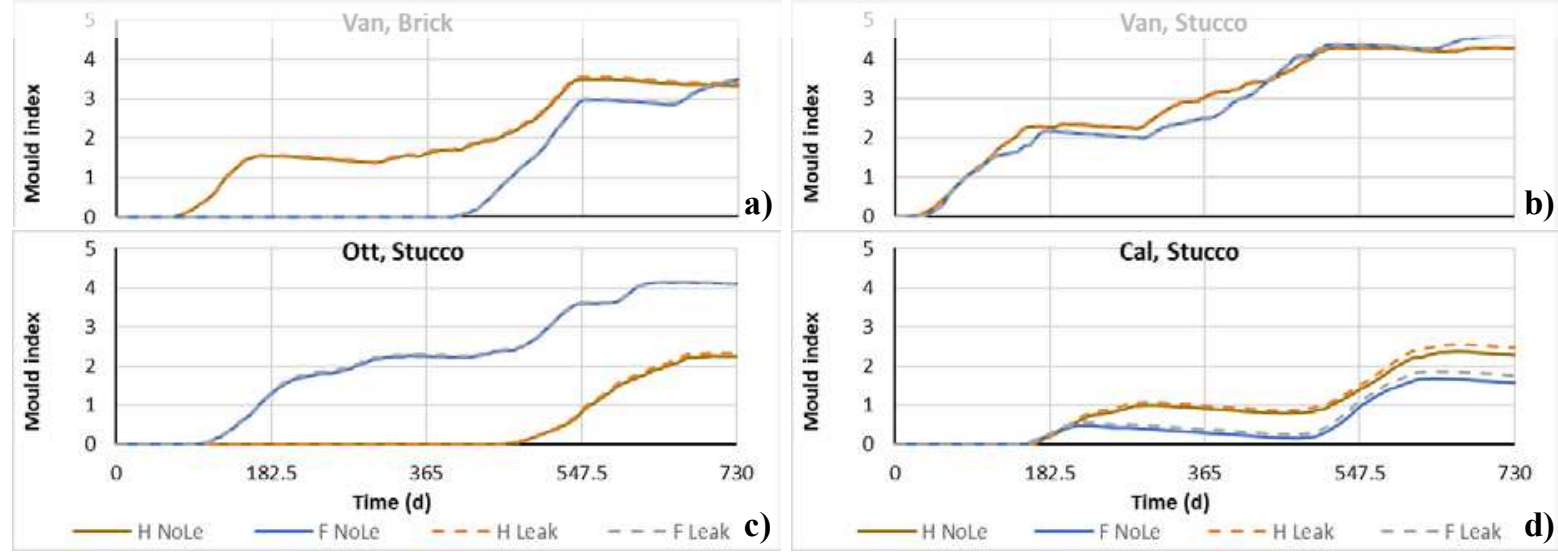

Figure 3. Mould index profiles in the worst position of OSB for both claddings, historical $(\mathrm{H})$ and future $(\mathrm{F})$ scenarios, with (Leak) and without (NoLe) air leakage.

In an attempt to assess the effect of future climate on the risk of mould growth, the difference between the maximum mould index for the cases with and without air leakage was calculated 
for both historical and future periods. Table 5 shows the maximum mould values and the difference between historical and future scenarios, with and without air leakage. Those values are labeled as "Leak - NoLe" in the shaded columns.

Table 5. Maximum mould index in the worst position of OSB for each case.

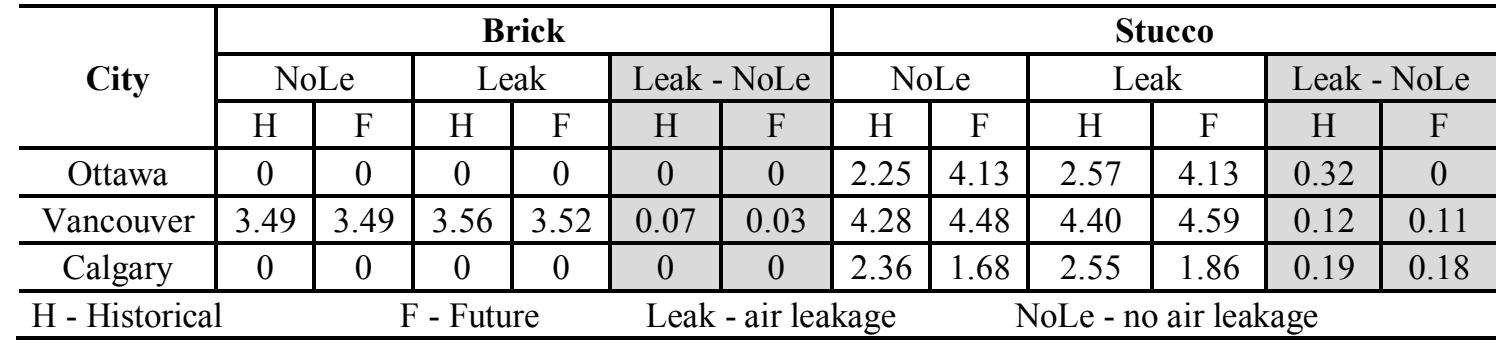

Although this calculation is not exactly true because hygrothermal behavior is a combination of all the factors, it gives an idea of the influence of the air leakage itself. It can be seen that air leakage led to higher mould indices in all cases since the exfiltration process brings more humid air to the cavity. Also, the lower values of "Leak - NoLe" in the future suggest that there might be a decrease in the risk of mould growth due to air leakage in the future.

As a general observation of Figure 3 and Table 5, air leakage has a greater impact when the mould index is low, since the major factor responsible for mould growth is the moisture coming from brick and stucco layers. If this amount of moisture is already high, the contribution of the moisture brought to the cavity by the air leakage is very low wh means low impact over

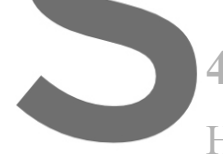

\section{Conclusions}

Hygrothermal perfornance of two wall assen
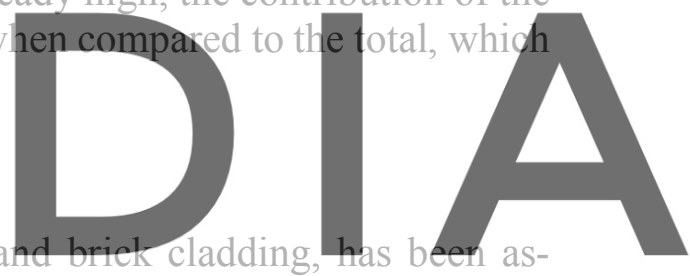

sessed in three cities under historical and future climate with and without air leakage to see their

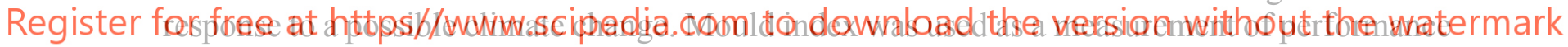
and the main findings for the cities and the wall configuration considered are:

Future climate in Ottawa presents higher amount of WDR when comparing with historical, which means the moisture content of the assembly is higher and so is the risk of mould growth. In Calgary, the amount of rain is similar in both climates but the temperature is higher in the future, which means more drying potential and less mould development. Vancouver is rainy in both scenarios and the mould indices are similarly high.

- Brick cladding is safer than stucco in any case in future climate. The higher moisture capacity of the brick, the wider drainage cavity and the higher air temperature all together increase the drying capacity of the assembly, which helps on keeping lower levels of relative humidity and lower mould indices. This situation is more evident in Ottawa and Calgary, which have no mould with this cladding.

- Air leakage increases the mould development in all cases, but the differences are small and cannot be blamed for major changes in the indices. The results suggest risk to mould growth may decrease in the future climate. 


\section{ORCID}

Max Junginger:

Maurice Defo:

Travis Moore:

Michael Lacasse:

Vanderley John:
0000-0002-7112-8584

0000-0001-9212-6599

0000-0002-4920-9193

0000-0001-7640-3701

0000-0002-0588-8382

\section{References}

ASHRAE. (2016). ASHRAE 160 [Criteria for Moisture-Control Design Analysis in Buildings]. ASHRAE Standards Committe.

ASHRAE. (2017). ASHRAE Handbook of fundamentals. ASHRAE Standards Committe.

Bush, E. and Lemmen, D. S. (Eds.). (2019). Canada's changing climate report. Government of Canada. http://publications.gc.ca/collections/collection_2019/eccc/En4-368-2019-eng.pdf

Cornick, S., Djebbar, R. and Dalgliesh, W. A. (2003). Selecting moisture reference years using a Moisture Index approach. Building and Environment, 38(12), 1367-1379. https://doi.org/10.1016/S0360-1323(03)00139-2

Gaur, A., Lacasse, M. and Armstrong, M. (2019). Climate Data to Undertake Hygrothermal and Whole Building Simulations Under Projected Climate Change Influences for 11 Canadian Cities. Data, 4(2), 72. https://doi.org/10.3390/data4020072

Gradeci, K., Labonnote, N., Time, B. and Köhler, J. (2017). Mould growth criteria and design avoidance approaches in wood-based materials - A systematic review. Construction and Building Materials, 150, 77-88. https://doi.org/10.1016/j.conbuildmat.2017.05.204

IPCC. (2014). Climate change 2014: Synthesis report. Contribution of Working Groups I, II and III to the Fifth Assessment Report of the Intergovernmental Panel on Climate Change [Core Writing Team, R.K. Pachauri and L.A. Meyer (eds.)] (p. 151). IPCC.

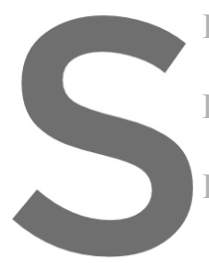

ISO. (2017). ISO 6946 [B transmittance-Calculation meth

Kumaran, M. K., Lackey, J. transport property datab

Lacasse, M. A., Defo, M. resilience of buildings to cnrc.gc.ca/eng/view/object/?id=757e8bd5-90f3-46.5

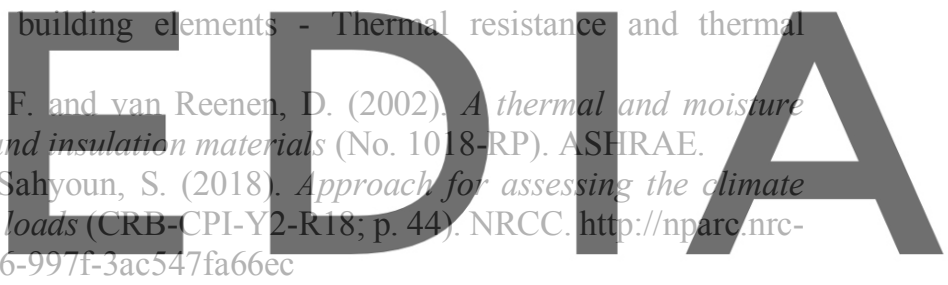

Lacasse, M. A., Ge, H., Hegel, M., Jutras, R., Laouadi, A., Sturgeon, G. and Wells, J. (2018). Guideline on design

Register forforedratihttps 45b6a70c-e5a7-419a-bb1a-4687435c7895.

NRC. (2015). National Building Code of Canada. National Research Council.

Ojanen, T. and Kumaran, M. K. (1992). Air Exfiltration and Moisture Accumulation in Residential Wall Cavities. Thermal Performance of the Exterior Envelopes of Buildings $V$, 491-500.

Ojanen, T. and Kumaran, K. (1996). Effect of Exfiltration on the Hygrothermal Behaviour of a Residential Wall Assembly. Journal of Thermal Insulation and Building Envelopes, 19(3), 215-227. https://doi.org/ 10.1177/ 109719639601900303.

Ojanen, T., Viitanen, H., Peuhkuri, R., Lähdesmäki, K., Vinha, J. and Salminen, K. (2010). Mold Growth Modeling of Building Structures Using Sensitivity Classes of Materials. Eleventh International Conference on Thermal Performance of the Exterior Envelopes of Whole Buildings, 10.

Saber, H. H. (2014). Report on Properties and Position of Materials in the Building Envelope for Housing and Small Buildings (No. A1-004615; p. 108). NRC-CNRC.

Sedlbauer, K. (2001). Prediction of mould fungus formation on the surface of and inside building components [Thesis (Doctorate)]. Sttutgart Universitat.

Vereecken, E. and Roels, S. (2012). Review of mould prediction models and their influence on mould risk evaluation. Building and Environment, 51, 296-310. https://doi.org/10.1016/j.buildenv.2011.11.003.

Vereecken, E., Saelens, D. and Roels, S. (2011). A comparison of different mould prediction models. 12th Conference of International Building Performance Simulation Association, 8.

Viitanen, H., Krus, M., Ojanen, T., Eitner, V. and Zirkelbach, D. (2015). Mold Risk Classification Based on Comparative Evaluation of Two Established Growth Models. Energy Procedia, 78, 1425-1430. https://doi.org/10.1016/j.egypro.2015.11.165. 